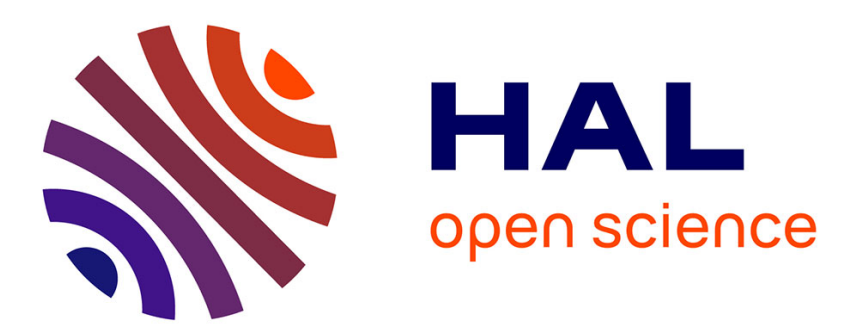

\title{
Sodium bicarbonate ingestion prior to training improves mitochondrial adaptations in rats
}

David J. Bishop, Claire Thomas, Thomas Moore-Morris, Michail Tonkonogi, Kent Sahlin, Jacques Mercier

\section{- To cite this version:}

David J. Bishop, Claire Thomas, Thomas Moore-Morris, Michail Tonkonogi, Kent Sahlin, et al.. Sodium bicarbonate ingestion prior to training improves mitochondrial adaptations in rats. AJP Endocrinology and Metabolism, 2010, 299 (2), pp.225-233. hal-01585953

\section{HAL Id: hal-01585953 https://hal-insep.archives-ouvertes.fr/hal-01585953}

Submitted on 12 Sep 2017

HAL is a multi-disciplinary open access archive for the deposit and dissemination of scientific research documents, whether they are published or not. The documents may come from teaching and research institutions in France or abroad, or from public or private research centers.
L'archive ouverte pluridisciplinaire HAL, est destinée au dépôt et à la diffusion de documents scientifiques de niveau recherche, publiés ou non, émanant des établissements d'enseignement et de recherche français ou étrangers, des laboratoires publics ou privés. 



\title{
Sodium bicarbonate ingestion prior to training improves mitochondrial
}

\section{adaptations in rats}

\author{
David J. Bishop, ${ }^{1,2}$ Claire Thomas, ${ }^{3,5}$ Tom Moore-Morris, ${ }^{3}$ Michail Tonkonogi, ${ }^{6,7}$ Kent Sahlin, ${ }^{7,8}$ \\ and Jacques Mercier ${ }^{3,4}$ \\ ${ }^{1}$ Institute of Sport, Exercise, and Active Living; ${ }^{2}$ School of Sport and Exercise Science, Victoria University, Melbourne, \\ Victoria, Australia; ${ }^{3}$ Université Montpellier, Unité de Formation et de Recherche (UFR) Médecine, EA4202; ${ }^{4}$ Institut \\ National de la Sante et de la Recherche Medicale, ERI 25, F-34000, Montpellier; ${ }^{5}$ Université Evry Val d'Essonne, UFR \\ Sciences Fondamentales et Appliquées, Département Sciences et Techniques des Activités Physiques et Sportives, EA3872, \\ U902, F-91025, Evry, France; ${ }^{6}$ Lugnet Institute of Sport Science, Dalarna University, Falun; ${ }^{7}$ The Swedish School of Sport \\ and Health Sciences; and ${ }^{8}$ Karolinska Institutet, Stockholm, Sweden
}

We tested the hypothesis that re- ducing hydrogen ion accumulation during training would result in greater improvements in muscle oxidative capacity and time to exhaustion (TTE). Male Wistar rats were randomly assigned to one of three groups (CON, PLA, and BIC). CON served as a sedentary control, whereas PLA ingested water and BIC ingested sodium bicarbonate $30 \mathrm{~min}$ prior to every training session. Training consisted of seven to twelve 2-min intervals performed five times/wk for $5 \mathrm{wk}$. Following training, TTE was significantly greater in BIC (81.2 \pm 24.7 min) compared with PLA (53.5 $\pm 30.4 \mathrm{~min})$, and TTE for both groups was greater than $\mathrm{CON}(6.5 \pm 2.5 \mathrm{~min})$. Fiber respiration was determined in the soleus (SOL) and extensor digitorum longus (EDL), with either pyruvate (Pyr) or palmitoyl carnitine (PC) as substrates. Compared with $\mathrm{CON}\left(14.3 \pm 2.6 \mathrm{nmol} \mathrm{O} \mathrm{O}_{2} \cdot \mathrm{min}^{-1} \cdot \mathrm{mg}\right.$ dry $\left.\mathrm{wt}^{-1}\right)$, there was a signifi greater SOL-Pyr state 3 respiration in both PLA (19.6 \pm $3.0 \mathrm{nmol} \mathrm{O}_{2} \cdot \mathrm{min}^{-1} \cdot \mathrm{mg}$ dry $\left.\mathrm{wt}^{-1}\right)$ and BIC $(24.4 \pm 2.8 \mathrm{nmol}$ $\mathrm{O}_{2} \cdot \mathrm{min}^{-1} \cdot \mathrm{mg}$ dry $\mathrm{wt}^{-1}$ ), with a significantly greater value in BIC. However, state 3 respiration was significantly lower in the EDL from both trained groups compared with CON. These differences remained significant in the SOL, but not the EDL, when respiration was corrected for citrate synthase activity (an indicator of mitochondrial mass). These novel findings suggest that reducing muscle hydrogen ion accumulation during running training is associated with greater improvements in both mitochondrial mass and mitochondrial respiration in the soleus.

mitochondrial respiration; state 3 respiration; muscle $\mathrm{pH}$; citrate synthase; muscle buffer capacity

MITOCHONDRIA ARE CENTRAL TO THE CONVERSION of energy by oxidizing substrates and generating the cell fuel ATP. During steady-state exercise, the rate of mitochondrial ATP production is closely matched to the rate of ATP hydrolysis, and this demonstrates the existence of efficient cellular mechanisms to control mitochondrial ATP synthesis. However, there is evidence that the maximal rate of mitochondrial ATP production $\left(V_{\max }\right)$ is in excess of that which is required during exercise with large muscle groups (e.g., 2-legged exercise) (52). Nonetheless, despite this apparent overcapacity, there are further

Address for reprint requests and other correspondence: D. Bishop, Institute of Sport, Exercise, \& Active Living, Victoria University, P. O. Box 14428, Melbourne, Victoria 8001 Australia (e-mail: david.bishop@vu.edu.au). increases in $V_{\max }$ with endurance training $(14,53,59)$. Although this adaptation will have little influence on whole body maximal oxygen utilization, it will play a major role in reducing metabolic perturbations and increasing time to exhaustion (TTE) during submaximal exercise (18). In contrast, reduced mitochondrial respiration appears to provide an important mechanism that links a low aerobic capacity to the pathogenesis of cardiovascular disease (63) and insulin resistance (33). Regularly performed exercise can result in a rapid increase in

the activities of oxidative enzymes (26), mitochondrial density (56), and mitochondrial respiration (14, 49, 53, 54, 60). However, given the importance of mitochondrial respiration for both performance and health, further research is required to determine factors that regulate training-induced changes in mitochondrial respiration. One potential factor, unexplored to date, is the degree of acidosis experienced during training. We have reported recently that reducing $\mathrm{H}^{+}$accumulation during training (via pretraining ingestion of sodium bicarbonate, $\mathrm{NaHCO}_{3}$ ) resulted in greater improvements in both short-term endurance and the lactate threshold in humans (20). Because the lactate threshold has previously been correlated with mitochondrial respiration (28), we hypothesized that this finding may have been due to the positive effects of reducing $\mathrm{H}^{+}$ accumulation during training on training-induced changes in mitochondrial respiration.

When a molecular view on training adaptation is taken, it is apparent that adaptations to training are the consequence of changes in gene expression that lead to the accumulation of specific proteins. It has been shown that the muscle environment (e.g., low glycogen) is a determining factor for the transcription of some genes in response to training (40). Recent research suggests that cellular $\mathrm{pH}$ may also affect the traininginduced expression of some genes, in particular, nuclearencoded genes that have been proposed to regulate mitochondrial biogenesis [e.g., peroxisome proliferator-activated receptor--y coactivator-1a. (PGC-1a.)] $(5,38)$. Such findings further suggest that reducing $\mathrm{H}^{+}$accumulation during training may promote mitochondrial adaptations.

Therefore, the present study investigated for the first time the effects of altering muscle $\mathrm{pH}$ during training (via $\mathrm{NaHCO}_{3}$ ingestion) on citrate synthase (CS) activity (a marker of mitochondrial mass) and mitochondrial respiration in rat skeletal muscle. Although many previous studies have investigated the effects of training on the function of isolated mitochondria (7, $30,43)$, the structure of the mitochondrial membrane and the 
Table 1. Summary of the training performed by both training groups during the experimental period

\begin{tabular}{|c|c|c|c|c|c|}
\hline Training Weeks & 1 & 2 & 3 & 4 & 5 \\
\hline No. of intervals/training session & 7 & 7 & 9 & 10 & 12 \\
\hline Mean speed/wk, m/min & 33 & 35 & 39 & 44 & 48 \\
\hline Minimal speed at the beginning of the training session, $\mathrm{m} / \mathrm{min}$ & 28 & 28 & 31 & 31 & 37 \\
\hline Maximal speed reached during the training session, $\mathrm{m} / \mathrm{min}$ & 37 & 40 & 43 & 49 & 52 \\
\hline Mean running distance/training session, $\mathrm{m}$ & 435 & 489 & 731 & 962 & 1,202 \\
\hline
\end{tabular}

function of the isolated mitochondria may be altered by the isolation procedure (45). Therefore, we chose to investigate the effects of training on mitochondrial respiration in saponinpermeabilized fibers, since it is possible to study mitochondria in situ, keeping their natural environment (46). We hypothesized that rats ingesting $\mathrm{NaHCO}_{3}$ prior to every training session (BIC) would have a significantly greater maximal, ADPstimulated (state 3) respiration than either sedentary rats $(\mathrm{CON})$ or rats ingesting water prior to training (PLA). In addition, we hypothesized that, despite performing identical training, BIC would have a greater submaximal TTE than PLA.

\section{METHODS}

\section{Ethical Approval}

The experimental protocol was approved by the Research Ethics Committee of the University of Montpellier and conducted according to the guidelines of the National Research Council for the Care and Use of Laboratory Animals and French law on animal handling and protection.

\section{Animals}

Twenty-one male Wistar rats (Charles River Laboratories, St. Germain sur l'Arbresle, France) were housed individually in a temperature-controlled room and maintained with food and drink ad libitum in a 12:12-h light-dark cycle (lights on at $7 \mathrm{PM}$ ), thus allowing exercise during their active phase. All exercise tests were conducted in the daytime, but a dark cover was placed over the treadmill to ensure that the rats exercised in darkness. The body mass of the rats was monitored throughout the experimental period.

\section{Experimental Design}

All animals were familiarized with a motor-driven treadmill for 3-4 days, $5 \mathrm{~min} /$ day, on a $10 \%$ grade. The running speed was initially $15 \mathrm{~m} / \mathrm{min}$ and was gradually increased to $25 \mathrm{~m} / \mathrm{min}$ within 2 days. Following the familiarization, all animals performed an incremental test to exhaustion on a treadmill inclined to $15^{\circ}$ [starting at $10 \mathrm{~m} / \mathrm{min}$ with increments of $3 \mathrm{~m} / \mathrm{min}$ every $2 \mathrm{~min}$ (24)]. At least $72 \mathrm{~h}$ later, the rats performed a TTE test at the individually determined maximal velocity reached during the incremental test. Exhaustion in both tests was defined as the inability of the rats to run on the treadmill despite small electric shocks and an inability to upright themselves when placed on their back.

Rats were then randomly assigned to one of the following three groups: a control group that performed no training (CON; $n=7)$, a high-intensity training group supplemented with a placebo (PLA; $n=$ 7), or a high-intensity training group supplemented with sodium bicarbonate (BIC; $n=7$ ). At least $72 \mathrm{~h}$ after the last training session, rats performed a TTE test at the pretraining maximal velocity reached during the incremental test (without supplementation). Seventy-two hours after the last exercise, all rats were euthanized by cervical dislocation. One of the soleus (SOL) and extensor digitorum longus (EDL) muscles was quickly removed, frozen in liquid nitrogen, and stored at ${ }^{-} 80^{\circ} \mathrm{C}$ until biochemical analysis. Before freezing, a section of the sample was mounted in embedding medium and frozen in isopentane cooled to its freezing point in liquid nitrogen. This sample was stored at $-80^{\circ} \mathrm{C}$ until later histochemical analysis. The same muscles were removed from the contralateral hindlimb, placed in an ice-cold preservation buffer on ice, and immediately prepared for fiber respiration measurements.

\section{Training Intervention}

As shown in Table 1, training consisted of seven (1st wk) to 12 (5th wk) 2-min intervals (interspersed with 1 min of rest) performed five times/wk for $5 \mathrm{wk}$. The intensity of the intervals was initially set at $80 \%$ of the peak speed reached for each rat during the incremental test and was increased by $10 \%$ each week. Rats were matched, on the basis of the peak speed reached during the incremental test, with a rat from the alternate training group, and both rats trained concurrently on the treadmill for each training session to ensure that all pairs performed identical amounts of training.

\section{Supplementation}

Thirty minutes prior to each training session, PLA received water, whereas BIC received $\mathrm{NaHCO}_{3}(0.05 \mathrm{~g} / \mathrm{kg}$ body mass $)$ administered by esophageal catheter. The timing and dose were based on our pilot work, which showed that there was a significant increase in blood $\mathrm{pH}$ 15-30 min after the administration of $\mathrm{NaHCO}_{3}$, which was maintained to a steady state for $>60$ min (Fig. 1) (51). In addition, our further pilot work demonstrated that the decrease in muscle $\mathrm{pH}$ immediately following a typical training session (6 X 2-min intervals interspersed with $1 \mathrm{~min}$ of rest) was significantly less following the administration of $\mathrm{NaHCO}_{3}$ than without in the SOL $[6.83 \pm 0.04$ (range: $6.76-6.87$ ) vs. $6.94 \pm 0.03$ (range: $6.90-6.97$ ) $\mathrm{pH}$ units, $P<$ $0.05]$ and tended to be less in the EDL [6.60 \pm 0.04 (range: 6.54-6.66) vs. $6.65 \pm 0.04$ (range: $6.58-6.70$ ) $\mathrm{pH}$ units in the EDL, $P>0.05]$. Although the range of $\mathrm{pH}$ values is greater than that which we have observed in our previously published human studies, we believe that this can be explained by the time required to remove the rat from the treadmill, perform the cervical dislocation, remove the fur, extract the muscles, and place them in liquid nitrogen. Because muscle $\mathrm{pH}$ can increase by 0.1 of a $\mathrm{pH}$ unit within $30 \mathrm{~s}$ postexercise (6), small differences in any of these postexercise procedures will obviously contribute to the variability of the reported measurements.

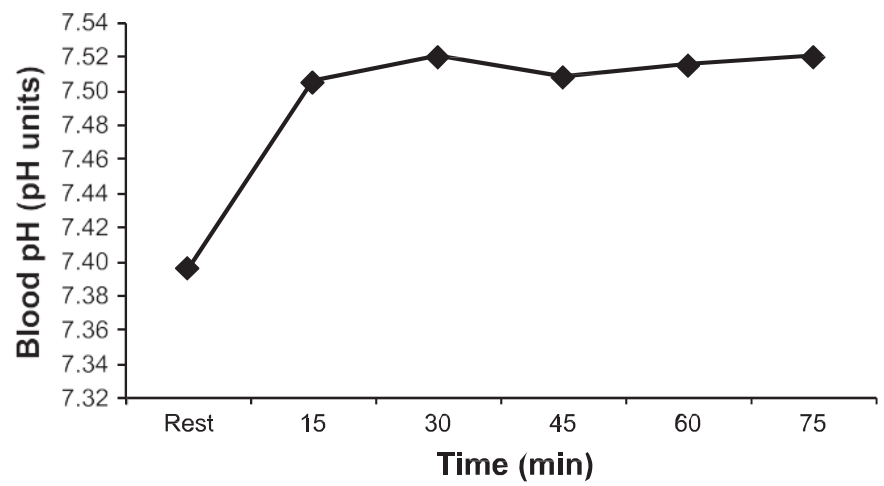

Fig. 1. Evolution of blood $\mathrm{pH}$ after administration of sodium bicarbonate $\left(\mathrm{NaHCO}_{3}\right)$ by esophageal catheter. 


\section{Skeletal Muscle Analyses}

Histochemical determination of fiber type. Serial transverse sections $\left(10-\mu \mathrm{m}\right.$-thick cross-sections) were cut in a cryostat at $-20^{\circ} \mathrm{C}$ and mounted on glass coverslips. The samples were stained for myofibrillar ATPase according to the procedure of Mabuchi and Sreter (34). The stained slides were photographed with a CMOS Pro camera (Sound Vision) connected to Nikon eclipse 400 microscope (Nikon, Tokyo, Japan). Computer image analysis was performed using the National Institutes of Health Image Analysis software (National Institutes of Health, Bethesda, MD), and muscle samples were classified as types I, IIa, and IIb.

Muscle buffer capacity. Resting muscle samples (45-50 mg) were homogenized on ice for $2 \mathrm{~min}$ in a solution containing sodium fl $\quad(10 \mathrm{mM})$ at a dilution of $25 \mu \mathrm{l}$ homogenizing solution/mg wet wt muscle (based on Ref. 35). The muscle homogenate was then placed in a circulating water bath at $37^{\circ} \mathrm{C}$ for 5 min prior to and during the measurement of $\mathrm{pH}$. The $\mathrm{pH}$ measurements were made with a microelectrode (MI-415; Microelectrodes, Bedford, $\mathrm{NH}$ ) connected to a $\mathrm{pH}$ meter (SA 520; Orion Research, Cambridge, MA). After initial $\mathrm{pH}$ measurement, muscle homogenates were adjusted to a $\mathrm{pH}$ of $\$ 7.2$ with a sodium hydroxide $(0.1 \mathrm{M})$ solution and then titrated to a $\mathrm{pH}$ of $\$ 2.2$ by the serial addition of $10 \mu \mathrm{l}$ of hydrochloric acid $(0.01 \mathrm{M})$. From the fi titration trend line, the number of moles of $\mathrm{H}^{+}$(per gram of wet muscle) required to change the $\mathrm{pH}$ from 7.1 to 6.5 was interpolated. This value was then normalized to the whole $\mathrm{pH}$ unit for fi display as micromoles $\mathrm{H}^{+}$per gram wet muscle per unit $\mathrm{pH}\left(\mu \mathrm{mol} \mathrm{H}^{+}\right.$. g muscle wet $\left.\mathrm{wt}^{-1} \cdot \mathrm{pH}^{-1}\right)$ and determined as the rat's muscle buffer capacity $\left(\mathrm{r} 3 \mathrm{~m}_{\text {in vitro }}\right)$.

CS and 6-phosphofructokinase activities. Homogenates for CS activity were prepared in buffer (in mM: 210 sucrose, 2 EGTA, 40 $\mathrm{NaCl}, 30 \mathrm{HEPES}, 5$ EDTA, and 2 phenylmethylsulfonyl fl

$\mathrm{pH}$ 7.4) and stored at $-80^{\circ} \mathrm{C}$. CS activity was assayed by a spectrophotometric method according to Srere (48). Changes in absorbance were recorded over $3 \mathrm{~min}$ at $412 \mathrm{~nm}$ and at $25^{\circ} \mathrm{C}$. Phosphofructokinase (PFK) activity was determined on fresh SOL and EDL homogenates according to Opie and Newsholme's (37) method and followed the rate of decrease in NADH at $340 \mathrm{~nm}$ and at $25^{\circ} \mathrm{C}$.

\section{Fiber Respiration}

Preparation of permeabilized fibers. Fibers were isolated from the SOL and the EDL muscles and each placed into $5 \mathrm{ml}$ of buffer $A$ [10 mM EGTA, $5 \mathrm{mM} \mathrm{MgCl} 2,20 \mathrm{mM}$ taurine, $0.5 \mathrm{mM}$ DTT, $5 \mathrm{mM}$ ATP, $20 \mathrm{mM}$ imidazole, $0.1 \mathrm{M}$ MES potassium salt (KMES), 15 $\mathrm{mM}$ phosphocreatine, $\mathrm{pH} 7.0$ ] with $50 \mu \mathrm{g} / \mathrm{ml}$ saponin for $20 \mathrm{~min}$ at $4{ }^{\circ} \mathrm{C}$. The saponin was then removed by rinsing the fi at two 10 min intervals at $4^{\circ} \mathrm{C}$ using $2 \times 5 \mathrm{ml}$ of ice-cold buffer $B(10 \mathrm{mM}$ EGTA, $5 \mathrm{mM} \mathrm{MgCl}_{2}, 20 \mathrm{mM}$ taurine, $0.5 \mathrm{mM}$ DTT, $20 \mathrm{mM}$ imidazole, $0.1 \mathrm{M}$ KMES, $3 \mathrm{mM}$ phosphate, $5 \mathrm{mg} / \mathrm{ml}$ bovine serum albumin, $\mathrm{pH}$ 7.0).

Assessing permeabilized fiber oxygen consumption. For all animals, the respiratory parameters of the total mitochondrial population of SOL and EDL muscle fibers were studied in situ using a Clark electrode (Strathkelvin Instruments, Glasgow, UK). Measurements were carried out at $30^{\circ} \mathrm{C}$ with continuous stirring in $2 \mathrm{ml}$ of the oxygraph solution with different respiratory substrates. The oxygen concentration in the medium used was $150 \mathrm{nmol} / \mathrm{ml}$. It consisted of buffer $B$ supplemented with $20 \mu \mathrm{M}$ EDTA, $50 \mu \mathrm{M} \mathrm{AP}_{5} \mathrm{~A}$ (an inhibitor of adenylate kinase), and $1 \mathrm{mM}$ iodoacetate and is referred to here as buffer $B=$. Eight to $10 \mathrm{mg}$ wet weight of permeabilized SOL and EDL fibers was placed into their respective oxygen chambers along with 2 $\mathrm{ml}$ of buffer $B=$ and respiratory substrates. Two metabolic pathways were investigated by using two pairs of respiratory substrates. One set of measurements was made using $10 \mathrm{mM}$ of pyruvate plus $10 \mathrm{mM}$ of malate (Pyr); the procedure was then repeated using $10 \mathrm{mM}$ of palmitoyl carnitine plus $10 \mathrm{mM}$ malate (PC), producing a second set of measurements for each muscle. A low oxygen consumption rate (state 2) was left to establish over a 5-min period, and then $2 \mathrm{mM}$ of ADP was injected into the chambers, resulting in an increase in respiration (state 3 ). After 5 min of state 3 respiration, respiration was inhibited using $70 \mu \mathrm{M}$ atractyloside (inhibitor of mitochondrial inner membrane ATP/ADP exchange) and $1 \mu \mathrm{M}$ oligomycin (ATP synthase inhibitor). The respiratory control ratio (RCR) was also calculated and is the quotient of state 3 respiration (with ADP in excess) over that of stage 4 (respiration inhibited).

\section{Statistical Analysis}

Descriptive statistics are expressed as means \pm SD. One-way ANOVA was performed to compare the effects of high-intensity training (comparison with $\mathrm{CON}$ ) and the effects of $\mathrm{NaHCO}_{3}$ administration (PLA vs. BIC). Individual relationships between variables were studied by means of linear regressions. SigmaStat software was used for all tests, and the level of signifi was set at $P<0.05$.

\section{RESULTS}

\section{Body Mass}

The mean body mass of the three groups of rats before training was $235 \pm 17 \mathrm{~g}$. After $5 \mathrm{wk}$ of treadmill training, the body masses of the PLA and BIC rats were $376 \pm 12$ and $375 \pm$ $18 \mathrm{~g}$, respectively, with no significant difference between groups. After 5 wk of caged living, the control rats $(426 \pm 24$ g) weighed significantly more than both training groups.

\section{CS and PFK Enzyme Activities}

As shown in Fig. 2, compared with CON, the activity of CS in the trained groups was higher for both PLA and BIC in the SOL $(P<0.05)$ and significantly lower for both training groups in the EDL. There was also significantly greater PFK activity $(P<0.05)$ in the SOL only for both trained groups, without a significant main effect for groups in the EDL $(P=$ $0.35)$.

\section{Fiber Respiration}

SOL. Compared with CON, both training groups had a signifi greater SOL-Pyr state 3 respiration $(+39 \pm 26$ and $+74 \pm 29 \%$ for PLA and BIC, respectively, $P<0.05)$, with a signifi greater value in BIC compared with PLA $(P=0.009)$ (Fig. 3). When the respiration was related to $\mathrm{CS}$ activity, a marker of mitochondrial mass, respiration remained signifi higher for BIC compared with CON $(P=0.006)$. Compared with $\mathrm{CON}$, the RCR in SOL-Pyr was signifi greater in both the PLA $(+43 \pm 25 \%, P<$ $0.001)$ and the $\mathrm{BIC}(+77 \pm 22 \%, P<0.001)$, with a signifi difference between the two training groups $(P=$ 0.016). There were no signifi differences between the groups for any of the respiration measurements for SOL-PC.

$E D L$. Compared with $\mathrm{CON}$, there was a signifi lower state 3 respiration in the two training groups when either Pyr $(-32 \pm 11$ and $-33 \pm 11 \%$ for PLA and BIC, respectively, $P=0.002)$ or $\mathrm{PC}(-23 \pm 23$ and $-32 \pm 12 \%$ for PLA and BIC, respectively, $P=0.009)$ was used as substrate; there were no signifi differences between the two training groups for either substrate. A similar pattern was observed for state 4 respiration. However, there were no 
Fig. 2. Citrate synthase (CS) and phosphofructokinase (PFK) enzyme activities in the 3 groups [a control group that performed no training $(\mathrm{CON})$, a high-intensity training group supplemented with a placebo (PLA), and a highintensity training group supplemented with sodium bicarbonate (BIC)] for both the soleus (SOL) and the extensor digitorum longus (EDL) muscles. Data are means $\pm \mathrm{SD} ; n=7$ for each group. *Signifi different from CON.
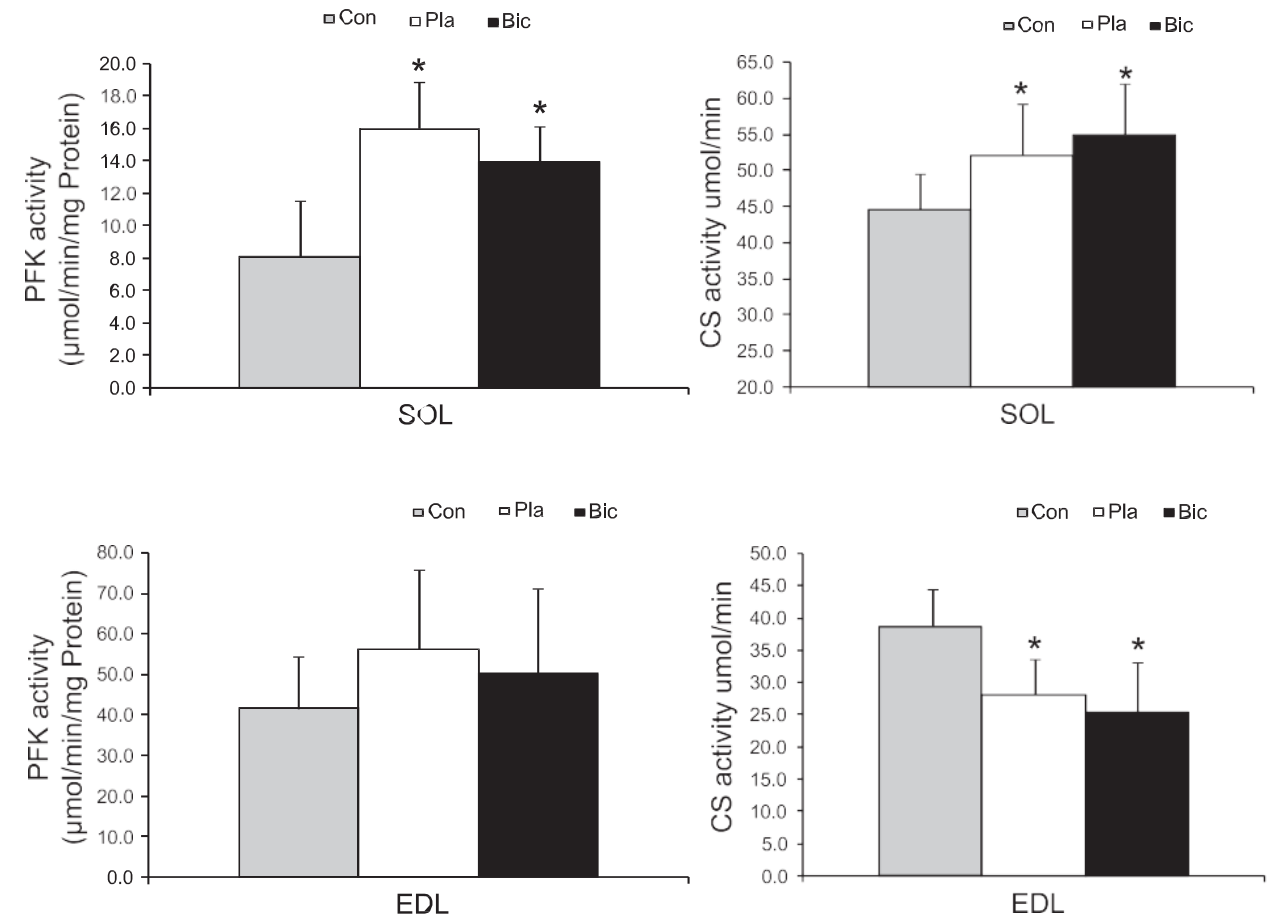

signifi differences between the three groups for state 3 respiration expressed relative to $\mathrm{CS}$ activity, or for the RCR, using either substrate.

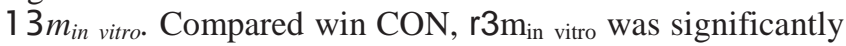
greater in both training groups (PLA and BIC) in both the soleus $(+40 \pm 29$ and $+34 \pm 19 \%$ for PLA and BIC, respectively, $P=0.001)$ and in the $\mathrm{EDL}(+22 \pm 15$ and $+22 \pm$ $29 \%$ for PLA and BIC, respectively, $P=0.02$ ) (Fig. 4).

\section{Fiber Composition}

There were no significant differences in fiber composition between the three groups (Fig. 5).

TTE

Following training, TTE was significantly greater in BIC $(81.2 \pm 24.7 \mathrm{~min})$ compared with PLA $(53.5 \pm 30.4 \mathrm{~min}, P=$
Fig. 3. State 3 respiration, state 3 respiration expressed relative to CS activity, state 4 respiration, state 4 respiration expressed relative to CS activity, and the respiratory control ratio (RCR) in the 3 groups in both the SOL and the EDL when either pyruvate + malate (Pyr) or palmitoyl carnitine + malate (PC) is used as substrates. *Significantly different from CON; †significantly different from PLA. Data are means \pm SD; $n=7$ for each group.
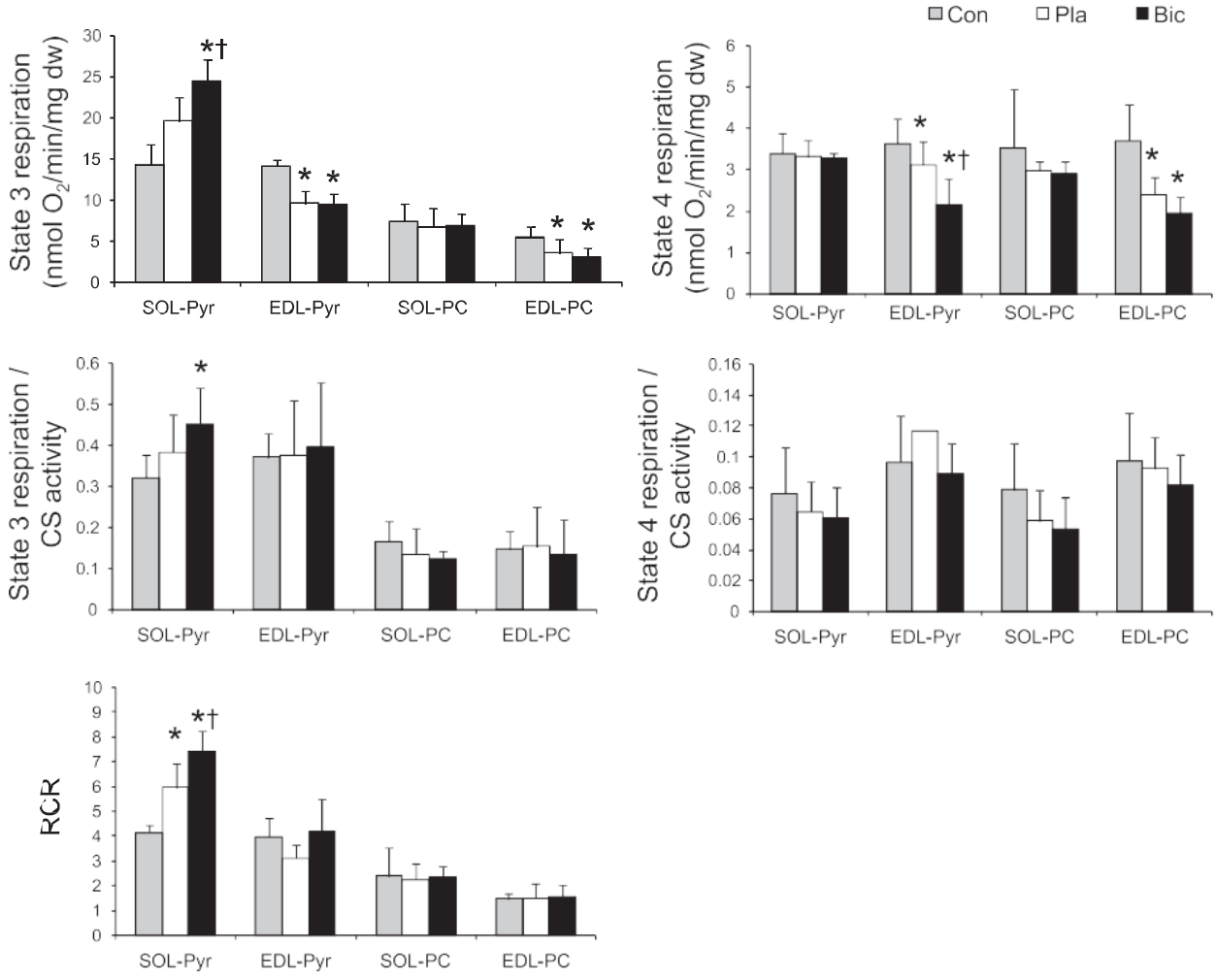


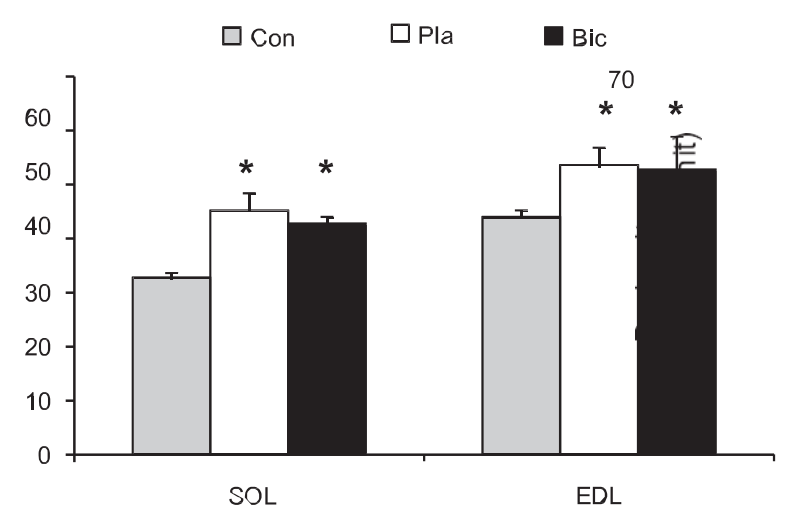

Fig. 4. Muscle buffer capacity ( $r 3 \mathrm{~m}_{\text {in vitro }}$ ) in the 3 groups for both the SOL and the EDL muscles. *Significantly different from CON. Data are means \pm SD; $n=7$ for each group.

$0.038)$, and TTE for both groups was greater than CON $(6.5 \pm$ $2.5 \mathrm{~min}, P<0.05)$. There was a significant correlation between state 3 respiration in the SOL (using PC as the substrate) and TTE in the two training groups (Fig. 6).

\section{DISCUSSION}

In the present study, training clearly increased muscle oxidative capacity in the soleus, as indicated by the greater state 3 fiber respiration (only with pyruvate as a substrate) and by the greater CS activity in trained rats. However, the main finding was that there was a significantly greater state 3 respiration in the soleus muscle of rats provided with $\mathrm{NaHCO}_{3}$ before every training session. We also report that there was a significant correlation between the state 3 respiration in the soleus and time to exhaustion.

In this study, we wanted to test specifically the hypothesis that reducing muscle $\mathrm{H}^{+}$accumulation during training would result in greater improvements in mitochondrial respiration. Thus, it was important to employ a training program that would result in large increases in mitochondrial respiration and a supplement protocol that would reduce the $\mathrm{H}^{+}$accumulation during training. Our training was based on previous research that has demonstrated that high-intensity interval training is required to increase the oxidative capacity of both the slowand fast-twitch fibers (white vastus lateralis) (19). Furthermore, to maximize adaptations in all rats, the imposed training intensity was based on the individually determined maximal running velocities of all rats, as recommended by others (62).

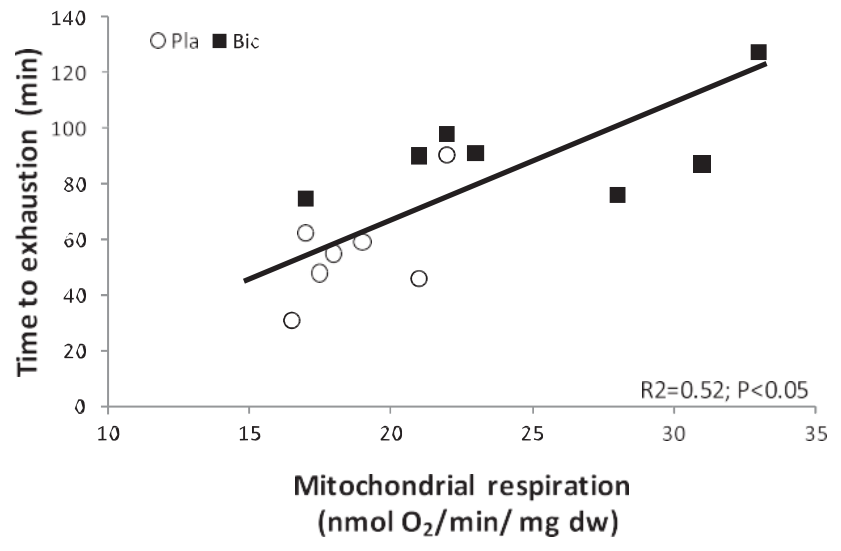

Fig. 6. Scatter plot showing the relationship between state 3 respiration in the SOL (with pyruvate and malate as substrates) and time to exhaustion in trained rats $(n=14)$.

Our supplement protocol was based on previous research in humans demonstrating that $\mathrm{NaHCO}_{3}$ ingestion leads to a smaller decrease in both blood (20) and muscle (13) $\mathrm{pH}$ following high-intensity interval training. In addition, our pilot work demonstrated that our $\mathrm{NaHCO}_{3}$ ingestion protocol significantly increased resting blood $\mathrm{pH}$ (Fig. 1) and reduced the decrease in muscle $\mathrm{pH}$ following a typical training session.

\section{Adaptations to the SOL}

The $25 \%$ greater CS activity in the soleus of trained rats (PLA and BIC; Fig. 2) following 5 wk of high-intensity interval training is consistent with previous reports (16-69\%) $(3,32,41,55,64)$. Because CS is an enzyme located exclusively in the mitochondria, it has been suggested to provide a good indication of directional changes in the mitochondrial mass (52). Thus, our results suggest that there was a greater mitochondrial mass in the soleus of our trained rats (with no significant difference between PLA and BIC).

Because the maximal activity of CS has been shown to have no correlation with the maximal flux through the tricarboxylic acid cycle $(8,12)$, it is difficult to infer changes in mitochondrial function with training from changes in the activity of this enzyme. Therefore, we measured maximal ADP-stimulated respiration and observed a significantly greater state 3 respiration in the soleus of the two trained groups (with pyruvate as a substrate) compared with the control group (Fig. 3). When considering the PLA and CON groups, these differences
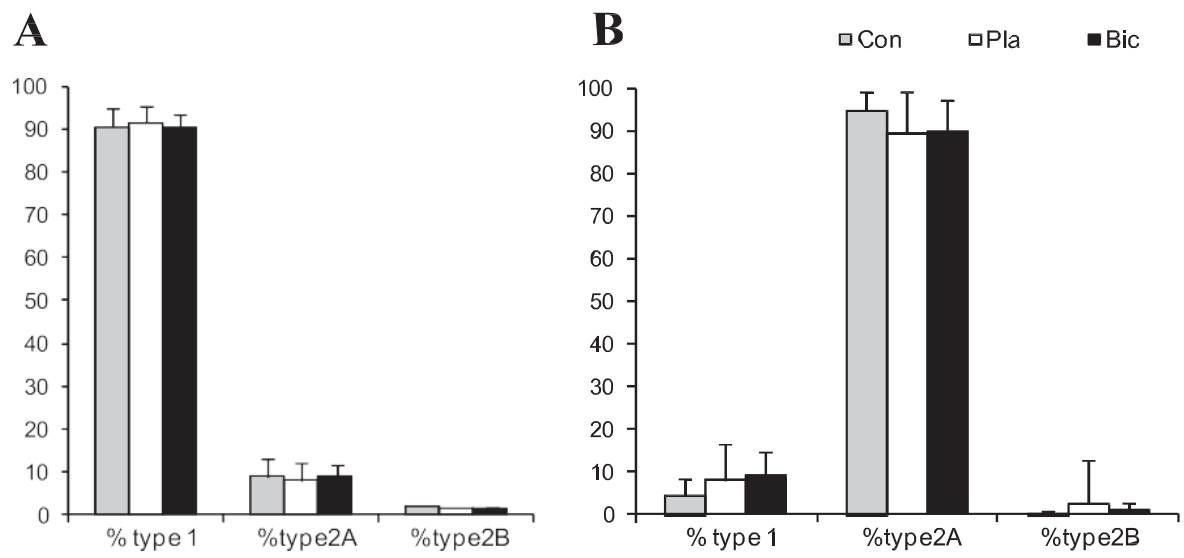

Fig. 5. \% Muscle fiber composition in the 3 groups for both the $\operatorname{SOL}(A)$ and the EDL $(B)$ muscles. Data are means $\pm \mathrm{SD} ; n=7$ for each group. 
(\$39\%) were similar to those reported in previous training studies using permeabilized fibers from both rats $(20-36 \%)(7$, 9) and humans $(36-38 \%)(15,59)$.

However, the most important finding of this study is that, compared with $\mathrm{CON}$, state 3 respiration was significantly greater in rats that were provided with $\mathrm{NaHCO}_{3}$ prior to every training session $(+74 \%$; BIC) than in rats that were supplied with the same volume of water prior to every training session (+39\%; PLA) (Fig. 3). This increase in BIC is nearly double that reported in previous studies that have reported changes in mitochondrial respiration in saponin-permeabilized fibers following training $(20-38 \%)(9,15,59)$. Furthermore, this difference remained significant even when corrected for CS activity. This suggests that both mitochondrial mass and mitochondrial function were significantly greater in BIC. Possible mechanisms are discussed below, but these novel findings indicate that reducing muscle $\mathrm{H}^{+}$accumulation during training is associated with greater improvements in mitochondrial respiration in the rat soleus.

\section{Potential Mechanisms}

Mitochondrial proteins are continuously degraded and renewed by de novo synthesis. This means that greater traininginduced changes in mitochondrial protein (mass) could occur as a result of reduced protein degradation and/or greater protein synthesis. Although we are unaware of any studies investigating the effects of acidosis on mitochondrial protein, skeletal muscle protein synthesis has been reported to be inhibited when the medium $\mathrm{pH}$ is lowered in a variety of cell and tissue culture systems $(21,22,58)$. In addition, acute metabolic acidosis has been reported to inhibit muscle protein synthesis (11) and to increase protein breakdown (42) in rat skeletal muscle. The protein breakdown pathway differs in mitochondria (ATP-dependent pathway involving mitochondrial proteases) vs. skeletal muscle (ATP-dependent pathway involving ubiquitin and proteasomes) (31). Nonetheless, it is possible that the greater state 3 respiration in BIC vs. PLA may be related to a smaller increase in mitochondrial protein degradation and/or reduced depression of mitochondrial protein synthesis as a result of smaller training-induced decreases in muscle $\mathrm{pH}$.

The degree of acidosis during training may also affect the expression of molecular signaling proteins and the subsequent transcription of nuclear-encoded genes that regulate mitochondrial biogenesis. To date, acidosis has been reported to affect protein kinase B/Akt phosphorylation (2), to increase mRNAs encoding ubiquitin and protease subunits $(1,27)$, and to activate MAPK/ERK signaling pathways (4). In addition, it has been reported recently that $\mathrm{NaHCO}_{3}$-induced chronic alkalosis promotes upregulation of PGC-1a. and some of its downstream targets (COX-II, COX-IV, and cytochrome $c$ ) in $\mathrm{C}_{2} \mathrm{C}_{12}$ myotubes (38). Furthermore, we have demonstrated recently that metabolic acidosis reduced exercise-induced upregulation of PGC-1a. mRNA (5). Thus, these latest findings suggest that our results may be explained, at least in part, by the effects of metabolic acidosis on the upregulation of important genes associated with mitochondrial biogenesis.

Although we have concentrated on the potential effects of acidosis on mitochondrial adaptations, $\mathrm{NaHCO}_{3}$ ingestion may exerts its effects by mechanisms in addition to, or instead of, alterations in exercise-induced muscle $\mathrm{pH}$. For example, it has been reported that the lactate anion also affects muscle-signaling pathways, leading to an increase in cytochrome $c$ oxidase (COX) mRNA and protein, and also PGC-1a. expression (23). An imposed metabolic alkalosis (following $\mathrm{NaHCO}_{3}$ ingestion) during high-intensity exercise produces an acceleration of glycogenolysis at the level of glycogen phosphorylase relative to maximal PDH activation, resulting in a mismatch between the rates of pyruvate production and oxidation, leading to an increase in lactate production (25). Thus, if lactate is indeed an important signaling molecule, greater increases in muscle lactate production during training, following $\mathrm{NaHCO}_{3}$ ingestion, may serve to promote even greater trained-induced changes in mitochondrial biogenesis.

\section{Adaptations to the EDL}

An unexpected finding was that there was a significantly lower $(335 \%)$ CS activity in the predominantly fast-twitch EDL muscle of our trained rats (Fig. 2). Other researchers have also reported lower (but not always significant) CS activity in the EDL (3-25\%) in response to training that was associated with significantly greater CS activity in the soleus (3, 32, 41, $57,64)$. It is possible that this can be attributed to a limited recruitment of the EDL during treadmill running in rats. However, if such an explanation is correct, one would expect no difference, rather than a lower CS activity, in the muscle of trained rats. The significantly greater $\mathrm{r} 3 \mathrm{~m}_{\text {in }}$ vitro in both the soleus and EDL muscle of the trained rats also argues in favor of both muscles being recruited during our training protocol.

An alternative explanation for the reported decrease in CS activity in the EDL is that our chosen training intensity was excessive for the EDL muscle. It has previously been reported that the optimal training intensity varies among different fiber types and that improvements in oxidative capacity (cytochrome $c$ activity) can be reduced with increases in training intensity (19). Furthermore, previous studies incorporating more moderate-intensity treadmill training in rats have reported significant increases in the CS of the EDL muscle (47, 50). Regardless of the explanation, our results suggest that high-intensity interval training can lead to a decrease in the mitochondrial mass of the EDL (a predominantly fast-twitch fiber), as indicated by the significantly lower CS activity in the EDL of trained rats.

Consistent with our CS results, we report for the first time that both state 3 and state 4 respiration were significantly lower in the EDL muscles from our trained rats compared with CON (Fig. 2). These differences were no longer apparent when mitochondrial respiration was corrected for CS activity. This suggests that the observed decreases in respiration were attributable to a lower mitochondrial mass rather than lower specific activity of the mitochondria. Furthermore, our observed decrease in CS is unlikely to be an artifact attributable to muscle hypertrophy (and hence, an apparent dilution of an unchanged total mitochondrial mass), since similar training in rats has not been reported to increase the mass of the EDL (168 \pm 26 vs. $170 \pm 17 \mathrm{~g}$ pre- and posttraining, respectively) (64). The absence of significant differences between BIC and PLA may be due to the observation that $\mathrm{NaHCO}_{3}$ ingestion was less effective in reducing the change in $\mathrm{pH}$ in the EDL. 


\section{Mitochondrial Respiration with Pyruvate vs. Palmitoyl Carnitine}

Endurance exercise training is typically associated with an increased contribution of lipids to energy metabolism during submaximal work (10). The mechanisms for this are not clear, but this adaptation has been attributed to increased mitochondrial volume (29), higher r3-oxidation enzyme capacity (39), and greater lipid oxidation rates by the mitochondria (61). Therefore, it is surprising that we did not observe an increase in the maximal ADP-stimulated respiration of the soleus when using palmitoyl carnitine as a substrate. However, to our knowledge, all previous studies that have observed traininginduced increases in mitochondrial respiration with palmitoyl carnitine as a substrate have used isolated mitochondria. An important difference when working with permeabilized skeletal muscle fibers is that reaching a concentration that is saturating requires a much greater palmitoyl carnitine concentration, and this high concentration may cause uncoupling in some mitochondria. This concern is supported by our respiration values for palmitoyl carnitine, which are less than one-half of the values for pyruvate, whereas these values are very similar when isolated mitochondria are used (36).

\section{Time to Exhaustion}

A final novel finding of the present study is that, in addition to having a greater state 3 respiration, rats in the BIC group also had a significantly greater time to exhaustion than PLA. Furthermore, there was a significant correlation $(r=0.72, P<$ 0.05 ) between state 3 respiration in the soleus (with pyruvate and malate as substrates) and time to exhaustion in trained rats (Fig. 6). This is consistent with previous research, which has suggested that muscle oxidative capacity is a major determinant of endurance performance (16-18). For example, it has been reported previously that there is a temporal association between improvements in muscle oxidative capacity and improvements in endurance time during iron repletion in irondeficient rats (18). Thus, the results of the present study provide further support for the hypothesis that muscle oxidative capacity is a major determinant of endurance performance. Furthermore, our results suggest that it is the oxidative capacity of the slow-twitch fibers that is a particularly important predictor of submaximal exercise time to fatigue.

\section{Summary}

The main purpose of the present study was to investigate whether reducing muscle $\mathrm{H}^{+}$accumulation during training would result in greater improvements in mitochondrial respiration. The success of our endurance training program was confirmed by the significantly greater CS activity in the soleus, but not the EDL, of trained rats. Thus, our results suggest that there was a greater mitochondrial mass in the soleus of our trained rats (with no significant difference between PLA and BIC). In contrast, it appears that high-intensity interval training can also lead to a decrease in the mitochondrial mass of the EDL (a predominantly fast-twitch fiber), as indicated by the significantly lower CS activity in the EDL of trained rats. However, the most important finding of this study is that, compared with $\mathrm{CON}$, state 3 respiration was significantly greater in the rats that took $\mathrm{NaHCO}_{3}$ prior to every training session $(+74 \%$; BIC) than in the rats that were supplied with water prior to every training session $(+39 \%$; PLA). This difference remained significant even when CS activity was used as a reference base, which suggests that both mitochondrial mass and mitochondrial function were significantly greater in BIC. Further research is required to determine whether these findings can be explained by the effects of acidosis on protein degradation, protein synthesis, or the expression of molecular signaling proteins and the subsequent transcription of nuclear-encoded genes that regulate mitochondrial biogenesis.

\section{ACKNOWLEDGMENTS}

We thank Guillaume Py for assistance with the histochemical analyses.

\section{DISCLOSURES}

No conflicts of interest, financial or otherwise, are declared by the author(s).

\section{REFERENCES}

1. Bailey JL, Wang X, England BK, Price SR, Ding X, Mitch WE. The acidosis of chronic renal failure activates muscle proteolysis in rats by augmenting transcription of genes encoding proteins of the ATP-dependent ubiquitin-proteasome pathway. J Clin Invest 97: 1447-1453, 1996.

2. Bailey JL, Zheng B, Hu Z, Price SR, Mitch WE. Chronic kidney disease causes defects in signaling through the insulin receptor substrate/phosphatidylinositol 3-kinase/Akt pathway: implications for muscle atrophy. J Am Soc Nephrol 17: 1388-1394, 2006.

3. Baker SK, McCullagh KJ, Bonen A. Training intensity-dependent and tissue-specific increases in lactate uptake and MCT-1 in heart and muscle. J Appl Physiol 84: 987-994, 1998.

4. Bento LM, Carvalheira JB, Menegon LF, Saad MJ, Gontijo JA. Effects of $\mathrm{NH} 4 \mathrm{Cl}$ intake on renal growth in rats: role of MAPK signalling pathway. Nephrol Dial Transplant 20: 2654-2660, 2005.

5. Bishop D, Edge J, Mundel T, Hawke E, Leikis M, Pilegaard H. Metabolic acidosis reduces exercise-induced up-regulation of PGC1alpha mRNA (Abstract). Med Sci Sports Exerc 40: S655, 2008.

6. Bishop D, Edge J, Thomas C, Mercier J. Effects of high-intensity training on muscle lactate transporters and postexercise recovery of muscle lactate and hydrogen ions in women. Am J Physiol Regul Integr Comp Physiol 295: R1991-R1998, 2008.

7. Bizeau ME, Willis WT, Hazel JR. Differential responses to endurance training in subsarcolemmal and intermyofibrillar mitochondria. $J$ Appl Physiol 85: 1279-1284, 1998.

8. Blomstrand E, Radegran G, Saltin B. Maximum rate of oxygen uptake by human skeletal muscle in relation to maximal activities of enzymes in the Krebs cycle. J Physiol 501: 455-460, 1997.

9. Burelle Y, Hochachka PW. Endurance training induces muscle-specific changes in mitochondrial function in skinned muscle fibers. J Appl Physiol 92: 2429-2438, 2002.

10. Carter SL, Rennie C, Tarnopolsky MA. Substrate utilization during endurance exercise in men and women after endurance training. Am J Physiol Endocrinol Metab 280: E898-E907, 2001.

11. Caso G, Garlick BA, Casella GA, Sasvary D, Garlick PJ. Acute metabolic acidosis inhibits muscle protein synthesis in rats. Am J Physiol Endocrinol Metab 287: E90-E96, 2004.

12. Cooney GJ, Taegtmeyer H, Newsholme EA. Tricarboxylic acid cycle flux and enzyme activities in the isolated working rat muscle. Biochem $J$ 200: 701-703, 1981 .

13. Costill DL, Verstappen F, Kuipers H, Janssen E, Fink W. Acid-base balance during repeated bouts of exercise: influence of HCO3. Int J Sports Med 5: 228-231, 1984.

14. Daussin FN, Zoll J, Dufour SP, Ponsot E, Lonsdorfer-Wolf E, Doutreleau S, Mettauer B, Piquard F, Geny B, Richard R. Effect of interval versus continuous training on cardiorespiratory and mitochondrial functions: relationship to aerobic performance improvements in sedentary subjects. Am J Physiol Regul Integr Comp Physiol 295: R264-R272, 2008.

15. Daussin FN, Zoll J, Ponsot E, Dufour SP, Doutreleau S, Lonsdorfer E, Ventura-Clapier R, Mettauer B, Piquard F, Geny B, Richard R. Training at high exercise intensity promotes qualitative adaptations of 
mitochondrial function in human skeletal muscle. J Appl Physiol 104: 1436-1441, 2008.

16. Davies KJ, Packer L, Brooks GA. Biochemical adaptation of mitochondria, muscle, and whole-animal respiration to endurance training. Arch Biochem Biophys 209: 539-554, 1981.

17. Davies KJ, Donovan CM, Refino CJ, Brooks GA, Packer L, Dallman PR. Distinguishing effects of anemia and muscle iron deficiency on exercise bioenergetics in the rat. Am J Physiol Endocrinol Metab 246: E535-E543, 1984.

18. Davies KJ, Maquire JJ, Brooks GA, Dallman PR, Packer L. Muscle mitochondrial bioenergetics, oxygen supply, and work capacity during dietary iron deficiency and repletion. Am J Physiol Endocrinol Metab 242: E418-E427, 1982.

19. Dudley GA, Abraham WM, Terjung RL. Influence of exercise intensity and duration on biochemical adaptations in skeletal muscle. J Appl Physiol 53: $844-850,1982$

20. Edge J, Bishop D, Goodman C. Effects of chronic $\mathrm{NaHCO}_{3}$ ingestion during interval training on changes to muscle buffer capacity, metabolism, and short-term endurance performance. J Appl Physiol 101: 918-925, 2006.

21. England BK, Chastain JL, Mitch WE. Abnormalities in protein synthesis and degradation induced by extracellular $\mathrm{pH}$ in $\mathrm{BC} 3 \mathrm{H} 1$ myocytes. $\mathrm{Am}$ J Physiol Cell Physiol 260: C277-C282, 1991

22. Fuller SJ, Gaitanaki CJ, Sugden PH. Effects of increasing extracellular $\mathrm{pH}$ on protein synthesis and protein degradation in the perfused working rat heart. Biochem J 259: 173-179, 1989.

23. Hashimoto T, Hussien R, Oommen S, Gohil K, Brooks GA. Lactate sensitive transcription factor network in L6 cells: activation of MCT1 and mitochondrial biogenesis. FASEB J 21: 2602-2612, 2007

24. Henderson KK, Wagner H, Favret F, Britton SL, Koch LG, Wagner PD, Gonzalez NC. Determinants of maximal $\mathrm{O}_{2}$ uptake in rats selectively bred for endurance running capacity. J Appl Physiol 93: 1265-1274, 2002.

25. Hollidge-Horvat MG, Parolin ML, Wong D, Jones NL, Heigenhauser GJ. Effect of induced metabolic alkalosis on human skeletal muscle metabolism during exercise. Am J Physiol Endocrinol Metab 278: E316E329, 2000.

26. Holloszy JO, Coyle EF. Adaptations of skeletal muscle to endurance exercise and their metabolic consequences. J Appl Physiol 56: 831-838, 1984.

27. Isozaki U, Mitch WE, England BK, Price SR. Protein degradation and increased mRNAs encoding proteins of the ubiquitin-proteasome proteolytic pathway in $\mathrm{BC} 3 \mathrm{H} 1$ myocytes require an interaction between glucocorticoids and acidification. Proc Natl Acad Sci USA 93: 1967-1971, 1996.

28. Ivy JL, Withers RT, van Handel PJ, Elger DH, Costill DL. Muscle respiratory capacity and fiber type as determinants of the lactate threshold. J Appl Physiol 48: 523-527, 1980.

29. Jeukendrup AE, Saris WH, Wagenmakers AJ. Fat metabolism during exercise: a review-part II: regulation of metabolism and the effects of training. Int J Sports Med 19: 293-302, 1998.

30. Krieger DA, Tate CA, McMillin-Wood J, Booth FW. Populations of rat skeletal muscle mitochondria after exercise and immobilization. $J$ Appl Physiol 48: 23-28, 1980.

31. Lecker S, Solomon V, Mitch W, Goldberg A. Muscle protein breakdown and the critical role of the ubiquitin-protease pathway in normal and disease states. J Nutr 129: 227S-237S, 1999.

32. Lemoine S, Granier P, Tiffoche C, Berthon PM, Rannou-Bekono F, Thieulant ML, Carre F, Delamarche P. Effect of endurance training on oestrogen receptor alpha transcripts in rat skeletal muscle. Acta Physio Scand 174: 283-289, 2002.

33. Lowell BB, Shulman GI. Mitochondrial dysfunction and type 2 diabetes. Science 307: 384-387, 2005.

34. Mabuchi K, Sreter F. Actomyosin ATPase II. Fibre typing by histochemical ATPase reaction. Muscle Nerve 3: 233-239, 1980.

35. Mannion AF, Jakeman PM, Willan PL. Determination of human skeletal muscle buffer value by homogenate technique: methods of measurement. J Appl Physiol 75: 1412-1418, 1993.

36. Mogensen M, Sahlin K. Mitochondrial efficiency in rat skeletal muscle: influence of respiration rate, substrate and muscle type. Acta Physiol Scand 185: 229-236, 2005

37. Opie L, Newsholme EA. The activities of fructose 1,6-diphosphatase, phosphofructokinase and phosphoenolpyruvate carboxykinase in white and red muscle. Biochem J 103: 391-399, 1967.
38. Perez-Schindler J, Philp A, Baar K. Sodium bicarbonate increases glucose uptake and mitochondrial biogenesis in $\mathrm{C} 2 \mathrm{C} 12$ myotubes potentially via the transcriptional co-activator PGC-1a (Abstract). Proc Physiol Soc 14: PC44, 2009.

39. Phillips SM, Green HJ, Tarnopolsky MA, Heigenhauser GJ, Grant SM. Progressive effect of endurance training on metabolic adaptations in working skeletal muscle. Am J Physiol Endocrinol Metab 270: E265E272, 1996.

40. Pilegaard H, Keller C, Steensberg A, Helge JW, Pedersen BK, Saltin B, Neufer PD. Influence of pre-exercise muscle glycogen content on exercise-induced transcriptional regulation of metabolic genes. $J$ Physiol 541: 261-271, 2002.

41. Plant DR, Gregorevic P, Warmington SA, Williams DA, Lynch GS. Endurance training adaptations modulate the redox-force relationship of rat isolated slow-twitch skeletal muscles. Clin Exp Pharmacol Physiol 30: 77-81, 2003.

42. Reaich D, Channon SM, Scrimgeour CM, Goodship TH. Ammonium chloride-induced acidosis increases protein breakdown and amino acid oxidation in humans. Am J Physiol Endocrinol Metab 263: E735-E739, 1992

43. Roussel D, Lhenry F, Ecochard L, Sempore B, Rouanet JL, Favier R. Differential effects of endurance training and creatine depletion on regional mitochondrial adaptations in rat skeletal muscle. Biochem J 350: 547-553, 2000.

44. Roy RR, Hutchison DL, Pierotti DJ, Hodgson JA, Edgerton VR. EMG patterns of rat ankle extensors and flexors during treadmill locomotion and swimming. J Appl Physiol 70: 2522-2529, 1991.

45. Saks VA, Kuznetsov AV, Khuchua ZA, Vasilyeva EV, Belikova JO, Kesvatera T, Tiivel T. Control of cellular respiration in vivo by mitochondrial outer membrane and by creatine kinase. A new speculative hypothesis: possible involvement of mitochondrial-cytoskeleton interactions. J Mol Cell Cardiol 27: 625-645, 1995.

46. Saks VA, Veksler VI, Kuznetsov AV, Kay L, Sikk P, Tiivel T, Tranqui L, Olivares J, Winkler K, Wiedemann F, Kunz WS. Permeabilized cell and skinned fiber techniques in studies of mitochondrial function in vivo. Mol Cell Biochem 184: 81-100, 1998.

47. Sanchez J, Bastien C, Monod H. Enzymatic adaptations to treadmil training in skeletal muscle of young and old rats. Eur J Appl Physiol 52: 69-74, 1983.

48. Srere P. Citrate synthase. Methods Enzymol 13: 3-5, 1969.

49. Starritt EC, Angus D, Hargreaves M. Effect of short-term training on mitochondrial ATP production rate in human skeletal muscle. $J$ Appl Physiol 86: 450-454, 1999.

50. Takekura H, Yoshioka T. Different metabolic responses to exercise training programmes in single rat muscle fibres. J Muscle Res Cell Motil 11: $105-113,1990$.

51. Thomas C, Bishop D, Moore-Morris T, Mercier J. Effects of highintensity training on MCT1, MCT4, and NBC expressions in rat skeletal muscles: influence of chronic metabolic alkalosis. Am J Physiol Endocrinol Metab 293: E916-E922, 2007.

52. Tonkonogi M, Sahlin K. Physical exercise and mitochondrial function in human skeletal muscle. Exerc Sport Sci Rev 39: 129-137, 2002.

53. Tonkonogi M, Sahlin K. Rate of oxidative phosphorylation in isolated mitochondria from human skeletal muscle: effect of training status. Acta Physiol Scand 161: 345-353, 1997.

54. Tonkonogi M, Walsh B, Svensson M, Sahlin K. Mitochondrial function and antioxidative defence in human muscle: effects of endurance training and oxidative stress. J Physiol 528: 379-388, 2000.

55. Troup JP, Metzger JM, Fitts RH. Effect of high-intensity exercise training on functional capacity of limb skeletal muscle. J Appl Physiol 60: 1743-1751, 1986

56. Turner DL, Hoppeler H, Claassen H, Vock P, Kayser B, Schena F, Ferretti G. Effects of endurance training on oxidative capacity and structural composition of human arm and leg muscles. Acta Physiol Scand 161: 459-464, 1997.

57. van Breda E, Keizer HA, Vork MM, Surtel DA, de Jong YF, van der Vusse GJ, Glatz JF. Modulation of fatty-acid-binding protein content of rat heart and skeletal muscle by endurance training and testosterone treatment. Pflugers Arch 421: 274-279, 1992.

58. Wallin B, Mørland J, Fikke AM. Combined effects of ethanol and $\mathrm{pH}-$ change on protein synthesis in isolated rat hepatocytes. Acta Pharma- col Toxicol (Copenh) 49: 134-140, 1981. 
59. Walsh B, Tonkonogi M, Sahlin K. Effect of endurance training on oxidative and antioxidative function in human permeabilized muscle fibres. Pflugers Arch 442: 420-425, 2001.

60. Walsh B, Tonkonogi M, Söderlund K, Hultman E, Saks V, Sahlin $\mathbf{K}$. The role of phosphorylcreatine and creatine in the regulation of mitochondrial respiration in human skeletal muscle. J Physiol 537: 971978, 2001.

61. Wibom R, Hultman E, Johansson M, Matherei K, Constantin-Teodosiu D, Schantz PG. Adaptation of mitochondrial ATP production in human skeletal muscle to endurance training and detraining. $J$ Appl Physiol 73: 2004-2010, 1992.
62. Wisløff U, Helgerud J, Kemi OJ, Ellingsen Ø. Intensity-controlled treadmill running in rats: $\dot{\mathrm{V}}_{2}$ max and cardiac hypertrophy. Am J Physiol Heart Circ Physiol 280: H1301-H1310, 2001.

63. Wisløff U, Najjar SM, Ellingsen O, Haram PM, Swoap S, Al-Share Q, Fernström M, Rezaei K, Lee SJ, Koch LG, Britton SL. Cardiovascular risk factors emerge after artificial selection for low aerobic capacity. Science 307: 418-420, 2005.

64. Zonderland ML, Bär PR, Reijneveld JC, Spruijt BM, Keizer HA, Glatz JF. Different metabolic adaptation of heart and skeletal muscles to moderate-intensity treadmill training in the rat. Eur J Appl Physiol Occup Physiol 79: 391-396. 